\title{
Qualidade física, química e sensorial de biscoitos tipo cookies elaborados com a substituição parcial da farinha de trigo por farinha desengordurada de gergelim
}

\author{
Physical, chemical and sensory quality of cookies elaborated \\ with partial substitution of wheat flour by defatted sesame flour
}

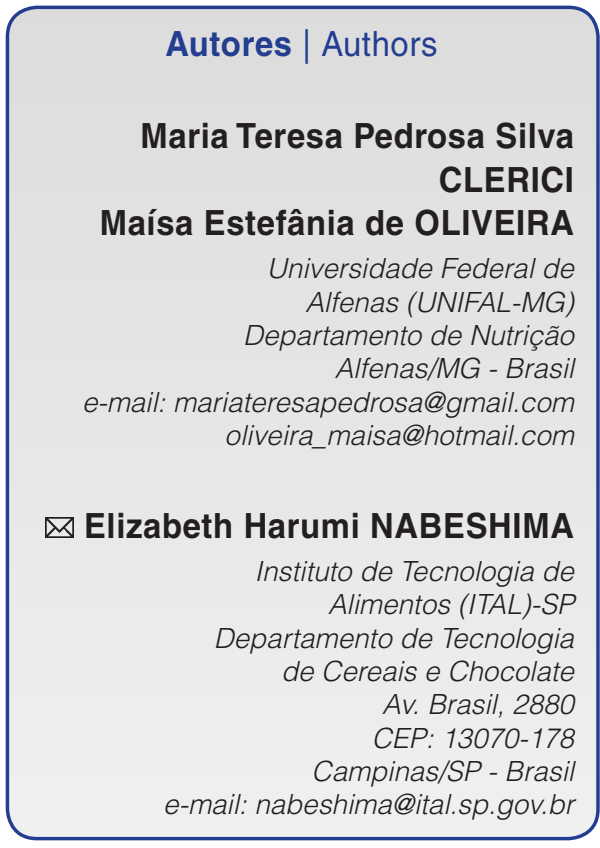

Autor Correspondente / Corresponding Author

Recebido / Received: 22/06/2012 Aprovado / Approved: 08/05/2013 Publicado / Published: jun./2013

\section{Resumo}

Os objetivos deste trabalho foram o desenvolvimento e a avaliação sensorial e físico-química de biscoitos tipo cookies com farinha desengordurada de gergelim (FDG), que é um subproduto da extração de óleo de gergelim. A partir de uma formulação padrão (F0), foram feitas substituições da farinha de trigo por FDG nos níveis de $10 \%$ (F1), 20 \% (F2) e 30 \% (F3). Foi realizado o teste de aceitação sensorial (textura, cor, sabor e aparência), bem como o teste de intenção de compra, para selecionar os cookies com maiores médias de aceitação, que foram analisados quanto às suas características tecnológicas e à composição centesimal. Para a avaliação sensorial, foi feita a análise de variância seguida de teste de Tukey $(p<0,05)$; para as demais análises, foi feito o teste de Student $(p<0,05)$. F0 e F1 foram selecionados pela avaliação sensorial, pois apresentaram significativamente os maiores valores para o sabor e a intenção de compra, em comparação com F2 e F3. Tecnologicamente, F0 e F1 não apresentaram diferença significativa em relação a densidade de massa, $a_{w}$, firmeza e atributos de cor $L^{*}$ e $b^{*}$, porém F0 apresentou os menores valores de volume específico e atributo de cor $\mathrm{a}^{*}$. A composição centesimal mostrou que o cookie F1 apresentou significativamente os maiores valores de cinzas (1,83\%), proteínas $(10,88 \%)$ e fibra alimentar (3,07\%), e menor teor de umidade (4,79\%), em comparação com F0. Foi possível obter biscoitos tipo cookies com substituição da farinha de trigo por até $10 \%$ de FDG, o que propiciou o aumento do teor de proteínas e fibra alimentar, com aceitação sensorial e características tecnológicas semelhantes ao cookie usado como controle.

Palavras-chave: Cookies; Farinha desengordurada de gergelim; Qualidade.

\section{Summary}

The objective of this work was the development and sensory and physicochemical evaluation of cookies with added defatted sesame flour (FDG), this being a by-product of the extraction of sesame oil. Based on a standard formulation (F0), the wheat flour was substituted with FDG at levels of $10 \%$ (F1), $20 \%$ (F2) and $30 \%$ (F3). The sensory acceptability (colour, texture, flavour and appearance) and purchasing intent were determined in order to select the cookies with greater acceptance means, which were analyzed for their proximate composition and technological characteristics. The results of the sensory evaluation were submitted to the analysis of variance followed by Tukey's test $(p<0.05)$, and the other results to the Student test $(p<0.05)$. F0 and F1 were selected by the sensory evaluation since they presented significantly higher values for taste and purchasing intent as compared to F2 and F3. F0 and F1 showed no significant technological differences in relation to mass density, aw, firmness and the colour attributes $L$ * and $b$ *, but F0 showed lower values for specific volume and the colour attribute $a^{*}$. In the proximate composition, the F1 cookies showed significantly higher values for ash $(1.83 \%)$, protein $(10.88 \%)$ and dietary fibre $(3.07 \%)$ and lower moisture contents $(4.79 \%)$ in comparison to F0. Cookies could be obtained with substitution of the wheat flour by up to $10 \%$ of FDG, leading to an increase in the protein and dietary fibre contents but with sensory acceptance and technological characteristics similar to those of the control cookie.

Key words: Cookies; Defatted sesame flour; Quality. 


\section{Introdução}

O Brasil ocupa a posição de segundo maior produtor mundial de biscoitos, com o registro de 1.206 milhões de toneladas em 2009 (SIMABESP, 2009).

Os biscoitos tipo cookies têm boa aceitação sensorial e comercial, sendo muito apreciados por crianças e adultos, e ainda possuem vida de prateleira relativamente longa. Muitos autores elaboraram cookies com redução de gordura (ZAMBRANO et al., 2002), adição de farinha de aveia (GUTKOSKI et al., 2007), farinha de soja e farelo de aveia (MARETI et al., 2010), farelo de trigo e arroz (FEDDERN et al., 2011), grãos de leguminosas (ZUCCO et al., 2011), farinha integral de cevada (GUPTA et al., 2011) e farinha de banana verde (AGAMA-ACEVEDO et al., 2012), sendo que os produtos apresentaram boa qualidade sensorial e tecnológica.

A farinha desengordurada de gergelim (FDG), um subproduto da extração de óleo, geralmente é usada na alimentação animal; contém proteínas, lipídeos, sais minerais, fibras e compostos antioxidantes (MOHDALY et al., 2011), o que demonstra o seu potencial para consumo humano.

A inclusão de ingredientes, que são fontes de fibras alimentares, em produtos alimentícios vem sendo estimulada (MELLO e LAAKSONEN, 2009), porém estes podem levar a mudanças sensoriais e tecnológicas. Portanto, o desenvolvimento e a otimização do produto final envolve a realização de testes físico-químicos e sensoriais - de consumidores -, de forma a se elaborarem formulações competitivas e de grande aceitação (SILVA et al., 1998).

O presente estudo teve o objetivo de substituir parcialmente a farinha de trigo por farinha desengordurada de gergelim para a produção de biscoitos tipo cookies, além de avaliá-los sensorialmente e caracterizar os produtos com melhor aceitação quanto às características tecnológicas e à composição química em nutrientes.

\section{Material e métodos}

\subsection{Matérias-primas}

Para a obtenção dos biscoitos tipo cookies, foram utilizados como ingredientes: farinha de trigo; farinha desengordurada de gergelim (FDG), e produtos adquiridos no comércio, como açúcar, essência de baunilha, xarope de glicose, margarina, fermento químico, condimentos (canela em pó, noz moscada e cravo em pó), sal, ovo in natura e água filtrada.

\subsection{Caracterização da farinha de trigo}

A farinha de trigo foi avaliada segundo métodos da AACC (2010), em relação à umidade, AACC Method
44-15.02; cinzas, AACC Method 08-12.01; teor de glúten úmido, AACC Method 38-12.02; número de queda foi determinado em equipamento Falling Number, marca Perten Instruments, AACC Method 56-81.03, sendo os resultados expressos em segundos; alveografia em alveógrafo modelo NG (Chopin, França), AACC Method 54-30.02, e farinografia em Farinógrafo Brabender, segundo AACC Method 54-21.02.

\subsection{Caracterização físico-química da FDG}

A composição centesimal foi realizada de acordo com a AACC (2010), com exceção da fibra alimentar, que foi avaliada segundo o método 991.43 da Associtation of Official Analytical Chemists (AOAC), descrito em HORWITZ (2005). A cor foi analisada em colorímetro modelo CR-10 (Konica Minolta, Japão), usando sistema CIE L* (Luminosidade, que vai do branco ao preto, mas é um valor que reflete a iluminação sobre a cor visualizada), $a^{*}$ (verde ao vermelho) e b* (azul ao amarelo) (MINOLTA, 2006).

\subsection{Formulação e produção de biscoitos tipo cookies}

Foi definida inicialmente uma formulação padrão (F0), a partir dos trabalhos de Silva et al. (1998). Na Tabela 1, pode ser visualizada a formulação padrão (F0) e aquelas com substituições parciais da farinha de trigo por $10 \%$ (F1), $20 \%$ (F2) e $30 \%$ (F3) de FDG.

A massa foi processada em batedeira planetária, marca Arno, utilizando-se batedor de massa média. Os ingredientes secos foram misturados por um minuto em velocidade baixa e, em seguida, foram adicionados os líquidos, que foram misturados por quatro minutos em velocidade média (até a obtenção do ponto ideal da massa).

A massa foi dividida em porções e aberta sobre o filme plástico com o auxílio de um rolo compressor. Os cookies foram cortados com o auxílio de cortadores de metal na espessura de $5 \mathrm{~mm}$ e $40 \mathrm{~mm}$ de diâmetro, e forneados a $250{ }^{\circ} \mathrm{C}$ por 15 minutos, em forno elétrico automático, marca Tropical. Os cookies foram resfriados por uma hora à temperatura ambiente, embalados em sacos plásticos e selados em seladoras elétricas, e armazenados em dessecadores por 24 horas, para em seguida serem analisados sensorial e tecnologicamente.

\subsection{Análise sensorial}

Para avaliar a aceitação dos cookies com FDG, foi realizado teste afetivo laboratorial pelo método da escala hedônica estruturada de nove pontos, que varia de 'gostei muitíssimo' (nota 9) a 'desgostei muitíssimo' (nota 1), de acordo com testes de aceitabilidade descritos por Meilgaard et al. (2006). Os atributos avaliados foram: 
Qualidade física, química e sensorial de biscoitos tipo cookies elaborados com a substituição parcial da farinha de trigo por farinha desengordurada de gergelim

CLERICI, M. T. P. S. et al.

Tabela 1. Formulações dos biscoitos tipo cookies apresentando a fórmula padrão (F0) e com 10 \% (F1), 20 \% (F2) e 30 \% (F3) de farinha desengordurada de gergelim (FDG).

\begin{tabular}{|c|c|c|c|c|}
\hline Ingredientes & Fo (0 \%) & F1 (10 \%) & F2 (20 \%) & F3 (30 \%) \\
\hline Farinha de trigo $(\mathrm{g})$ & 270,0 & 243,0 & 216,0 & 189,0 \\
\hline $\mathrm{FDG}^{1}(\mathrm{~g})$ & 0,0 & 27,0 & 54,0 & 81,0 \\
\hline Açúcar refinado (g) & 90,0 & 90,0 & 90,0 & 90,0 \\
\hline Xarope de glicose (g) & 10,0 & 10,0 & 10,0 & 10,0 \\
\hline Condimentos $^{2}(\mathrm{~g})$ & 0,5 & 0,5 & 0,5 & 0,5 \\
\hline Sal (g) & 1,0 & 1,0 & 1,0 & 1,0 \\
\hline Fermento químico (g) & 4,0 & 4,0 & 4,0 & 4,0 \\
\hline Margarina (g) & 62,5 & 62,5 & 62,5 & 62,5 \\
\hline Essência de baunilha (g) & 0,1 & 0,1 & 0,1 & 0,1 \\
\hline Gema (g) & 15,6 & 15,6 & 15,6 & 15,6 \\
\hline Água (mL) & 84,4 & 84,4 & 84,4 & 84,4 \\
\hline
\end{tabular}

${ }^{1}$ Porcentagem em relação ao peso inicial de farinha de trigo na F0. ${ }^{2}$ Cravo em pó, canela em pó e noz moscada.

aparência (uniformidade da cor, da superfície e do formato), aroma, sabor, textura e cor.

O teste de intenção de compra foi realizado utilizando-se escala estruturada de cinco pontos, que varia de 'certamente não compraria' (nota 1) a 'certamente compraria' (nota 5).

Este estudo contou com a participação de 71 provadores cujo perfil constituiu-se assim: quanto ao gênero, 25 \% masculino e 75 \% feminino; quanto à faixa etária, 52 \% em 20-30 anos; 34 \% em 15-20 anos; 7 \% em 40-50 anos, e $3 \%$ acima de 50 anos. As amostras foram servidas em escala monádica sequêncial, por sorteio, e em pratos plásticos brancos, codificados com números de três dígitos ao acaso, acompanhadas de um copo de água. Foi utilizada luz branca para iluminação das cabines. O trabalho foi aprovado pelo Comitê de Ética em Pesquisa (CEP) da Universidade Federal de Alfenas (UNIFAL-MG), sob n. ${ }^{\circ}$ 082/2010.

\subsection{Avaliação físico-química dos cookies}

\subsubsection{Densidade da massa crua}

A densidade foi obtida por meio da relação massa e volume, de acordo com o método 011/IV do Instituto Adolfo Lutz (BRASIL, 2005).

\subsubsection{Cor}

Foi realizada a avaliação segundo o item 2.3. Os resultados foram obtidos com nove repetições, para conseguir detectar alterações que podem ser advindas do assamento dos biscoitos, como posição ocupada e possibilidade de existência de gradiente de temperatura em várias regiões no forno (fundo, frente, laterais etc). Foi calculada a diferença de cor $(\Delta \mathrm{E})$ entre o cookie com FDG e o controle, segundo a Equação 1.
$\Delta \mathrm{E}=\left(\Delta \mathrm{L}^{* 2}+\Delta \mathrm{b}^{* 2}+\Delta \mathrm{a}{ }^{* 2}\right)^{1 / 2}$

em que: $\Delta \mathrm{E}=$ diferença de cor; $\Delta \mathrm{L}^{*}=\mathrm{Lp}$ (luminosidade do cookie padrão) - Lt (luminosidade do teste); $\Delta a^{*}=a p$ (valor de $a^{*}$ do cookie padrão) - at (valor de $a^{*}$ do teste); $\Delta b^{*}=b p\left(\right.$ valor de $b^{*}$ do cookie padrão) - bt (valor de $b^{\star}$ do teste).

\subsubsection{Textura instrumental}

A análise de textura foi realizada no sétimo dia após o processamento. A determinação de firmeza (parâmetro de textura) dos cookies foi realizada utilizando-se o texturômetro Stable Micro Systems Texture Analyser TAXT2. Foi utilizado probe 3-Point bending Rig (HDP/3PB) e plataforma HDP/90. Os resultados foram expressos em ' $N$ ' e representaram a média aritmética de 15 determinações de força de ruptura para amostras provenientes de um mesmo ensaio. Os parâmetros utilizados nos testes foram: velocidade pré-teste $=1,0 \mathrm{~mm} \cdot \mathrm{s}^{-1}$; velocidade de teste $=3,0 \mathrm{~mm} . \mathrm{s}^{-1}$; velocidade pós-teste $=10,0 \mathrm{~mm} . \mathrm{s}^{-1}$; distância 5 mm, com medida de força em compressão.

\subsubsection{Volume específico}

O volume específico foi calculado em triplicata pela relação entre o volume aparente (método de deslocamento de painço) e peso dos biscoitos após o forneamento, conforme Moraes et al. (2010).

\subsubsection{Atividade de água}

A atividade de água foi determinada, em triplicata, diretamente em medidor eletrônico da marca Decagon, modelo Aqualab lite, à temperatura constante $\left(25,0 \pm 0,30^{\circ} \mathrm{C}\right)$.

\subsubsection{Composição química}

Os teores de umidade, cinza, proteína, lipídeo e carboidrato foram avaliados segundo o item 2.3. O teor de fibra alimentar total foi feita de acordo com Horwitz (2005). 


\subsection{Análise estatística}

Todos os resultados da análise sensorial foram submetidos à análise de variância (ANOVA); quando esta foi significativa, realizou-se a comparação das médias pelo teste de Tukey $(p<0,05)$ para os testes sensoriais e a seleção dos cookies com os maiores escores. Diversamente, a comparação dos resultados físicoquímicos dos cookies mais aceitos foi feita pelo teste de Student $(p<0,05)$, usando-se o programa SAS (2003).

\section{Resultados e discussão}

\subsection{Caracterização da farinha de trigo}

$\mathrm{Na}$ Tabela 2, estão apresentados os resultados da análise de qualidade da farinha de trigo utilizada na elaboração dos cookies. Os resultados de umidade e de cinzas estão próximos aos descritos para farinha de trigo na Tabela Brasileira de Composição de Alimentos (UNICAMP, 2011). Para biscoitos tradicionais, a porcentagem de glúten na farinha de trigo deve ser de $26 \%$ a $29 \%$ para glúten úmido, e de $8 \%$ a $10 \%$ para glúten seco (FERREIRA, 2004). A porcentagem de glúten úmido da farinha analisada (32,27 \%) foi superior a esse valor, indicando que a farinha pode ser substituída por outras farinhas não formadoras de glúten, sem prejuízo da qualidade do produto final.

Em relação ao número de queda, a farinha de trigo deste trabalho se encontra dentro do especificado por Guarienti (1996), que indica número de queda superior a 150 segundos para biscoitos.

A Instrução Normativa n. ${ }^{\circ} 8$ de 30 de novembro de 2010 (BRASIL, 2010), chamada de 'Regulamento Técnico do Trigo', classifica o trigo de acordo com a sua força

Tabela 2. Características físico-químicas e reológicas da farinha de trigo.

\begin{tabular}{lc}
\multicolumn{1}{c}{ Análise } & Resultados \\
Cinzas $\left(\mathrm{g} .100 \mathrm{~g}^{-1}\right)$ & 0,70 \\
Umidade $\left(\mathrm{g} .100 \mathrm{~g}^{-1}\right)$ & 14,10 \\
Glúten úmido $(\%)$ & 32,27
\end{tabular}

\section{Falling Number}

Número de queda (s)

324

\section{Alveograma}

$\mathrm{P} / \mathrm{L}\left(\mathrm{mmHg} \cdot \mathrm{mm}^{-1}\right)$

W $\left(10^{-4} \mathrm{~J}\right)$

285

$\mathrm{L}(\mathrm{mm})$

21,00

\section{Farinograma}

Absorção de água (\%)

Tempo de desenvolvimento da massa (min)

Estabilidade (min)

Índice Tolerância Mistura (UF*)

33

* Unidades Farinográficas. de glúten (W), sendo considerado Trigo Melhorador, o que apresenta, no mínimo, $300 \times 10^{-4} \mathrm{~J}$ de W; Trigo para Pão, com no mínimo $220 \times 10^{-4} \mathrm{~J}$ de W; Trigo Doméstico, com no mínimo $160 \times 10^{-4} \mathrm{~J}$ de W, e Trigo Básico, com no mínimo $100 \times 10^{-4} \mathrm{~J}$. Para outros usos do trigo, se aceita qualquer valor de W. Dessa forma, a farinha utilizada é considerada como Trigo para Pão, por possuir força igual a $285 \times 10^{-4} \mathrm{~J}$, indicando ser adequada também para mesclas com outros tipos de farinha.

O farinograma avalia as características de mistura e hidratação da farinha, o desenvolvimento do glúten e a estabilidade da massa à mistura (AACC, 2010). A farinha de trigo utilizada pode ser considerada forte, uma vez que apresentou absorção de água superior a $58 \%$, estabilidade entre 8,0 e 15,0 min, e índice de tolerância à mistura entre 15 e 50 unidades farinográficas (UF), conforme citação de Pizzinatto et al. (1996). O tempo de desenvolvimento da massa está diretamente relacionado ao tempo de mistura necessário para que a mesma atinja seu ponto ótimo de desenvolvimento. O tempo de desenvolvimento encontrado (2,0 min) é classificado como sendo característico de farinha forte (YOUNG e CAUVAIN, 2007).

Estes resultados indicaram que a farinha utilizada foi apropriada para produção de pão, mas pode ser diluída com FDG, para a dimuição de sua força por meio da diluição do glúten, e produzir biscoitos com boas características tecnológicas.

\subsection{Caracterização da farinha desengordurada de gergelim}

A FDG apresentou $5,19 \% \pm 1,46$ de umidade; $17,80 \% \pm 0,45$ de cinzas; $24,06 \% \pm 0,30$ de lipídeos; $15,68 \% \pm 0,49$ de proteínas, e 37,26 \% de carboidratos, com fibra alimentar total de $32,41 \%$, sendo fibra solúvel de $8,13 \% \pm 0,26$ e fibra insolúvel de 24,27 \% $\pm 2,71$. No sistema Cie $L^{*} a^{*} b^{*}$, a cor foi $L^{*}=67,43 \pm 0,88$; $a^{*}=5,38 \pm 0,13, e b^{*}=17,20 \pm 0,48$.

A composição química da FDG apresentou teores de umidade e proteína inferiores aos valores encontrados por Maia et al. (1999), que foram de 7,21 e 59,16 \%, respectivamente, sendo que os teores de lipídeos e cinzas foram superiores aos encontrados. Comparando-se com os dados de Mohdaly et al. (2011), os resultados de lipídeos e proteínas estão semelhantes. Nascimento et al. (2012) obtiveram resultados para FDG diferentes deste trabalho e dos demais citados, pois obtiveram $35 \%$ de proteínas, $11,2 \%$ de lipídeos, 22,7 \% de fibra alimentar e $8,6 \%$ de cinzas. As variações na composição em nutrientes da FDG podem estar relacionadas às condições de processo de extração de óleo, à variedade do grão e às condições de cultivo. 
Qualidade física, química e sensorial de biscoitos tipo cookies elaborados com a substituição parcial da farinha de trigo por farinha desengordurada de gergelim

CLERICI, M. T. P. S. et al.

Não foram encontradas na literatura referências sobre os parâmetros de cor para FDG. Contudo, para se ter uma melhor referência com relação aos valores obtidos, Lustosa et al. (2008) obtiveram para a farinha de mandioca valores de $L^{*}=86,9$, coordenadas de cromaticidade $a^{*}=1,4$ e $b^{*}=14,1$. A FDG tende a ser mais escura do que a farinha de mandioca em relação ao parâmetro 'luminosidade'.

\subsection{Caracterização dos biscoitos tipo cookies}

\subsubsection{Avaliação sensorial dos biscoitos tipo cookies}

O perfil dos consumidores deste estudo reflete o ambiente universitário em que foi realizada a análise, pois o perfil de estudantes de graduação mostra que 53,5 \% dos estudantes das Universidades Federais são mulheres e 75 \% dos estudantes universitários são jovens na faixa etária de até 24 anos (ANDIFES, 2011).

As médias de aceitação e do teste de intenção de compra dos biscoitos formulados com diferentes níveis de substituição da farinha de trigo pela FDG estão indicadas na Tabela 3.

A formulação F1 obteve maior aceitação pelos provadores, pois não diferiu significativamente de F0 ( $p>0,05)$ em nenhum dos parâmetros. Em relação ao aroma e à cor, não houve diferenças significativas entre todas as formulações, porém F2 diferiu de F0 $(p<0,05)$ em relação ao sabor, e F3 diferiu em relação aos atributos 'aparência', 'sabor' e 'textura', tendo a menor aceitação sensorial.
Os resultados mostraram que o aumento da substituição da farinha de trigo por FDG interferiu na aceitação dos cookies pelos provadores. Nascimento et al. (2012) também obtiveram resultados de avaliação sensorial e tecnológica positivas quando produziram snacks de milho com $10 \%$ de FDG; notou-se que quando os consumidores recebiam a informação dos benefícios do uso do gergelim, eles aprovavam até $20 \%$ de FDG nos snacks extrusados de milho, o que mostra que o consumidor está em busca de produtos mais benéficos à saúde.

O teste de intenção de compra indicou que os provadores possivelmente comprariam Fo (cookie padrão) e F1, pois a média das notas de intenção de compra foi igual a 4. Já F2 e F3, com os menores escores, apresentaram diferença significativa em relação a F0.

$\mathrm{Na}$ medida em que a formulação F1 (10 \% de FDG) não apresentou diferença significativa em relação à aceitação sensorial e à intenção de compra em comparação à Fo, ela foi selecionada para os estudos físico-químicos comparativos com o padrão.

\subsubsection{Avaliação físico-química dos cookies}

As características físico-químicas dos cookies estão apresentadas na Tabela 4. Considerando-se a densidade da massa crua, verificou-se que F0 e F1 não apresentaram diferenças significativas $(p>0,05)$ entre si. Em seu estudo, Marangoni (2007) obteve biscoitos funcionais com farinha de yacon e aveia em flocos que também não diferiram entre si em relação à densidade da massa.

Tabela 3. Aceitabilidade e intenção de compra dos cookies Padrão (F0) e com 10 \% (F1), 20 \% (F2) e 30 \% (F3) de farinha desengordurada de gergelim. ${ }^{1}$

\begin{tabular}{|c|c|c|c|c|c|c|}
\hline Produto & Aparência & Aroma & $\begin{array}{c}\text { Aceitação }{ }^{2} \\
\text { Sabor }\end{array}$ & Textura & Cor & Intenção de compra ${ }^{3}$ \\
\hline F0 & $7,5 \pm 1,16^{a}$ & $7,3 \pm 1,52^{\text {n.s. }}$ & $8,00 \pm 1,17^{a}$ & $7,6 \pm 1,52^{a}$ & $7,4 \pm 1,56^{\text {n.s. }}$ & $4,3 \pm 0,83^{a}$ \\
\hline F1 & $6,9 \pm 1,68^{a b}$ & $7,2 \pm 1,33^{\text {n.s. }}$ & $7,6 \pm 1,15^{\mathrm{ab}}$ & $7,4 \pm 1,52^{a}$ & $7,0 \pm 1,69$ n.s. & $4,1 \pm 0,96^{a b}$ \\
\hline F2 & $7,4 \pm 1,26^{a}$ & $6,9 \pm 1,56^{\text {n.s. }}$ & $7,1 \pm 1,61^{\mathrm{b}}$ & $7,4 \pm 1,20^{a}$ & $7,4 \pm 1,36^{\text {n.s. }}$ & $3,7 \pm 1,11^{b}$ \\
\hline F3 & $6,7 \pm 1,62^{b}$ & $6,9 \pm 1,52^{\text {n.s. }}$ & $5,9 \pm 1,84^{c}$ & $6,3 \pm 1,80^{b}$ & $6,7 \pm 1,70^{\text {n.s. }}$ & $2,9 \pm 0,19 c$ \\
\hline
\end{tabular}

${ }^{1}$ Letras diferentes na mesma coluna diferem significativamente pelo teste de Tukey $(p<0,05)$ e n.s. = não significativo; ${ }^{2}$ Atributos das colunas: $5=$ não gostei e nem desgostei; $6=$ gostei ligeiramente; $7=$ gostei regularmente; ${ }^{3}$ Atributos da coluna: $2=$ possivelmente não compraria; 3 = talvez comprasse/talvez não comprasse; 4 = possivelmente compraria.

Tabela 4. Avaliação físico-química dos cookies padrão (F0) e com $10 \%$ de farinha desengordurada de gergelim (F1). ${ }^{1}$

\begin{tabular}{|c|c|c|c|c|c|c|c|c|}
\hline \multirow[b]{2}{*}{ Cookies } & \multirow{2}{*}{$\begin{array}{c}\text { Densidade da } \\
\text { massa } \\
\left(\mathrm{g} \cdot \mathrm{mL}^{-1}\right)\end{array}$} & \multirow[b]{2}{*}{ Aw } & \multirow{2}{*}{$\begin{array}{c}\text { Firmeza } \\
\text { (N) }\end{array}$} & \multirow{2}{*}{$\begin{array}{c}\text { Volume } \\
\text { específico } \\
\left(\mathbf{m g} \cdot \mathbf{g}^{-1}\right)\end{array}$} & \multicolumn{4}{|c|}{ Cor $^{2}$} \\
\hline & & & & & $L^{*}$ & $a^{*}$ & $\mathbf{b}^{*}$ & $\Delta E^{3}$ \\
\hline F0 & $7,12 \pm 0,85$ & $0,21 \pm 0,03$ & $8,18 \pm 0,96$ & $1,13 \pm 0,01$ & $63,71 \pm 3,60$ & $11,73^{*} \pm 1,52$ & $24,42 \pm 1,65$ & - \\
\hline F1 & $7,37 \pm 0,47$ & $0,21 \pm 0,01$ & $8,38 \pm 1,00$ & $1,37^{\star} \pm 0,03$ & $65,64 \pm 2,10$ & $9,85 \pm 2,13$ & $23,71 \pm 1,10$ & 2,79 \\
\hline
\end{tabular}

${ }^{1}$ Resultados apresentados em valores médios \pm desvio padrão e médias seguidas de * na horizontal diferem significativamente entre si pelo teste de Student $(p<0,05)$; ${ }^{2}$ cor L* (luminosidade ou brilho, variação de 0 a 100), cor $a^{*}$ (variação de verde a vermelho, de -60 a +60 ) e a cor b* (variação de azul a amarelo, $-60 \mathrm{a}+60) ;{ }^{3}$ diferença de cor. 
Não houve diferença significativa $(p>0,05)$ quanto à atividade de água entre F0 e F1, o que mostra que a atividade de água dos cookies elaborados ficou dentro da faixa de recomendação para esse tipo de produto, pois, de acordo com Sarantópoulos et al. (2001), a principal característica de biscoitos é sua baixa atividade de água, a qual se situa entre 0,1 e 0,3, garantindo estabilidade ao armazenamento. De acordo com Jardim (2010), mudanças físicas, como a crocância de biscoitos, dependem significativamente deste parâmetro. Segundo o autor, a mobilidade molecular e a viscosidade governam as transformações estruturais dependentes do tempo, como a cristalização, a aglomeração, a aderência, o colapso e a crocância. A viscosidade de alimentos sólidos amorfos é governada pela temperatura e pelo teor de água, acarretando mudanças na textura do produto. Dessa forma, a atividade de água traz informações importantes sobre a vida útil de um produto, bem como é um parâmetro do produto a ser modificado durante o processo de produção com o objetivo de aumentar a estabilidade dos alimentos; por exemplo, em cereais matinais, a aw deve ser inferior a 0,40 para evitar a perda de crocância, mas, em biscoitos, a aw deve ser inferior a 0,6 .

Quanto à firmeza instrumental dos cookies, pode-se avaliar que não houve variação significativa ( $p>0,05$ ) entre F0 e F1, o que indica que a adição de 10 \% de FDG não alterou tal parâmetro dos cookies. Os cookies produzidos neste trabalho apresentaram valores de firmeza ligeiramente menores aos encontrados por Zucco et al. (2011), que produziram cookies com leguminosas e obtiveram variações entre 8,7 e $15 \mathrm{~N}$, bem abaixo dos encontrados por Mareti et al. (2010), que verificaram alta dureza ( 85 a $218 \mathrm{~N}$ ) em biscoitos produzidos com a substituição parcial da farinha de trigo por misturas de farinha de soja, farelo de aveia e maltodextrina. Esta menor dureza dos biscoitos pode estar relacionada ao teor de lipídeos presente na FDG, que pode ter auxiliado no aumento da maciez do biscoito.

Os volumes específicos de F0 e de F1 ficaram próximos aos valores encontrados por Souza et al. (2001) ao avaliarem cookies de castanha do Brasil, encontrando valores que variaram de 0,97 a 1,41 ( $\left.\mathrm{mg} \cdot \mathrm{g}^{-1}\right)$.

Os valores de F0 e F1 diferiram significativamente $(p<0,05)$, sendo que a formulação F1 foi a que apresentou maior volume específico. O aumento do volume específico de cookies com a substituição da farinha de trigo também foi verificado por Feddern et al. (2011), quando esta foi substituída por 10 a $30 \%$ de farelo de arroz.

Em relação às coordenadas de cromaticidade, luminosidade e coordenada b* (variação de azul a amarelo correspondente a $-60 \mathrm{a}+60$, respectivamente), observou-se que não houve diferença significativa $(p>0,05)$ entre F0 e F1; porém, a coordenada $a^{*}$ apresentou redução significativa para F1, ou seja, os cookies desta formulação apresentaram-se com menor intensidade da tonalidade avermelhada.

Os cookies apresentados neste trabalho apresentaram menores valores de luminosidade $\left(L^{*}\right)$ do que os apresentados por Schober et al. (2003), para biscoitos isentos de glúten $\left(L^{*}=70,3\right.$ a 75,2$)$, e os de Marangoni (2007), para biscoitos funcionais com farinha de yacon e aveia em flocos $\left(L^{*}=72,8\right.$ a 76,93$)$.

Quanto à diferença de cor, Tiwari et al. (2008) classificaram analiticamente as diferenças perceptíveis na cor em: muito distintas, distintas e pouco distintas, quando o valor de $\Delta E$ for superior a 3,0, entre 1,5 e 3,0, e inferior a 1,5 , respectivamente. De acordo com esta classificação, pode-se afirmar que houve uma variação distinta na cor entre o cookie com 10 \% de FDG e o padrão.

Os resultados mostram que os cookies com $10 \%$ de FDG apresentaram características físico-químicas semelhantes ao cookie padrão, com variações somente no maior volume específico e na coloração mais escura.

\subsubsection{Composição química}

Na Tabela 5, estão apresentados os resultados da análise de composição centesimal dos cookies elaborados.

Em relação ao teor de umidade, observou-se que houve diferença significativa entre F0 e F1, porém ficaram dentro do descrito por Sarantópoulos et al. (2001), pois apresentaram umidade entre 2 e $8 \%$, o que thes confere crocância.

Os resultados mostraram que o teor de lipídeos não diferiu significativamente entre F0 e F1. Fasolin et al. (2007) elaboraram cookies a partir de farinha de banana e também encontraram valores semelhantes para o teor de lipídeos, que variaram de 18 a $19 \%$, que é bem superior ao teor de lipídeos dos cookies apresentados neste trabalho. O fato de o teor de lipídeos não apresentar diferença significativa neste trabalho pode ser em razão de a maior contribuição ser proveniente da margarina, que

Tabela 5. Composição centesimal dos ensaios dos cookies padrão (F0) e com 10 \% de farinha desengordurada de gergelim (F1). ${ }^{1}$

\begin{tabular}{lcc} 
Nutrientes $\left.\mathbf{( g . 1 0 0 ~} \mathbf{~ g}^{-\mathbf{1}}\right)$ & $\mathbf{F 0}$ & $\mathbf{F 1}$ \\
Umidade & $5,96^{\star} \pm 0,26$ & $4,79 \pm 0,04$ \\
Cinzas & $1,33 \pm 0,02$ & $1,83^{\star} \pm 0,08$ \\
Proteína & $9,46 \pm 0,49$ & $10,88^{*} \pm 0,18$ \\
Lipídeos & $11,97 \pm 0,13$ & $13,52 \pm 1,26$ \\
Carboidratos Totais & \\
Fibra alimentar & 71,28 & 68,9 \\
\hline
\end{tabular}

${ }^{1}$ Resultados apresentados em valores médios \pm desvio padrão e médias seguidas de $\left(^{*}\right)$ na horizontal diferem significativamente entre si pelo teste de Student $(p<0,05) .{ }^{2}$ Calculado pela diferença. 
Qualidade física, química e sensorial de biscoitos tipo cookies elaborados com a substituição parcial da farinha de trigo por farinha desengordurada de gergelim

CLERICI, M. T. P. S. et al.

se manteve em concentrações fixas, e também da baixa substituição da farinha de trigo pela FDS, que foi de $10 \%$.

F1 apresentou significativamente os maiores teores de cinzas e proteína do que Fo. Este resultado já era esperado por causa da substituição da farinha de trigo por FDG, que apresenta teores elevados destes dois nutrientes; na formulação FO, os valores destes nutrientes estão ligados à farinha de trigo e ao ovo, que se mantiveram em concentrações fixas. Nascimento et al. (2012) também observaram aumento de valores destes nutrientes em snacks de milho produzidos com 10 a $20 \%$ de FDG.

O teor de fibra alimentar foi maior significativamente nos cookies contendo a FDG, como o esperado, pois vários autores relataram o mesmo aumento de fibras com o uso de farinha de jatobá (SILVA et al., 1998) e farinha de aveia (GUTKOSKI et al., 2007).

\section{Conclusão}

Foi possível produzir cookies com o uso de até $10 \%$ de farinha desengordurada de gergelim (FDG) para substituir a farinha de trigo, pois estes apresentaram aceitação sensorial e propriedades físico-químicas semelhantes à formulação sem substituição; porém, a FDG contribuiu para aumentar os teores de sais minerais, proteínas e fibra alimentar do produto final.

\section{Agradecimentos}

Agradecemos à FAPEMIG, pelo apoio financeiro ao projeto sob n. ${ }^{\circ}$ CAG- APQ-01607-10; à PIBIC-CNPq, pela Bolsa de Iniciação Científica, e à Empresa Sésamo Real ${ }^{\circledR}$, pela doação da farinha desengordurada de gergelim.

\section{Referências}

AGAMA-ACEVEDO, E.; ISLAS-HERNÁNDEZ, J. J.; PACHECOVARGAS, G.; OSORIO-DÍAZ, P.; BELLO-PÉREZ, L. A. Starch digestibility and glycemic index of cookies partially substituted with unripe banana flour. LWT - Food Science and Technology, Amsterdam, v. 46, p. 177-182, 2012

AMERICAN ASSOCIATION OF CEREAL CHEMISTS - AACC. Approved Methods of Analysis. 11th ed. St. Paul: AACC International, 2010. Disponível em: <http://methods.aaccnet. org/toc.aspx>. Acesso em: 13 jan. 2011.

ASSOCIAÇÃO NACIONAL DOS DIRIGENTES DAS INSTITUIÇÕES FEDERAIS DE ENSINO SUPERIOR - ANDIFES. Perfil socioeconômico e cultural dos estudantes de graduação das universidades federais brasileiras. In: FÓRUM NACIONAL DE PRÓ-REITORES DE ASSUNTOS COMUNITÁRIOS E ESTUDANTIS - FONAPRACE, 2011, Brasília. Anais... Brasília, 2011. Disponível em: <http://www. andifes.org.br/index.php?option=com_docman\&task=doc_ download\&gid=635\&ltemid=27 >. Acesso em: 29 maio 2012.
BRASIL. Ministério da Saúde. Agência Nacional de Vigilância Sanitária. Métodos físico-químicos para análise de alimentos. 4. ed. Brasília: Ministério da Saúde, 2005. 1018 p.

BRASIL. Ministério da Agricultura, Pecuária e Abastecimento. Instrução Normativa n ${ }^{\circ} 38$, de 30 de novembro de 2010. Aprova o regulamento técnico do trigo. Diário Oficial da República Federativa do Brasil, Brasília, 01 jul. 2011. Seção 1.

FASOLIN, L. H.; ALMEIDA, G. C.; CASTANHO, P. S.; NETTOOLIVEIRA, E. R. Biscoitos produzidos com farinha de banana: avaliações química, física e sensorial. Ciência e Tecnologia de Alimentos, Campinas, v. 27, n. 3, p. 524-529, 2007. http:// dx.doi.org/10.1590/S0101-20612007000300016

FEDDERN, V.; DURANTE, V. V. O.; MIRANDA, M. Z. Avaliação física e sensorial de biscoitos tipo cookie adicionados de farelo de trigo e arroz. Brazilian Journal of Food Technology, Campinas, v. 14, n. 4, p. 267-274, 2011. http://dx.doi. org/10.4260/BJFT2011140400032

FERREIRA, D. T. L. Pesquisa com a mistura da fécula de mandioca. Revista da Associação Brasileira dos Produtores de Amido de Mandioca, Paranavaí, v. 2, n.7, jun./ago. 2004. Disponível em: <http://www.abam.com.br/revista/revista7/ pesq_mistura_fec.php $>$. Acesso em: 20 out. 2010.

GUARIENTI, E. M. Qualidade Industrial de Trigo. Passo Fundo: Embrapa Trigo, 1996. 36 p.

GUPTA, M.; BAWA, A. S.; ABU-GHANNAM, N. Effect of barley flour and freeze-thaw cycles on textural nutritional and functional properties of cookies. Food and Bioproducts Processing, Amsterdam, v. 89, p. 520-527, 2011. http://dx.doi.org/10.1016/j. fbp.2010.07.005

GUTKOSKI, L. C.; IANISKI, F.; DAMO, T. V.; PEDÓ, I. Biscoitos de aveia tipo "cookie" enriquecidos com concentrado de $\beta$-glicanas. Brazilian Journal of Food Technology, Campinas, v. 10, n. 2, p. 104-110, 2007.

HORWITZ, W. (Ed.). Official Methods of Analysis of the Association of Official Analytical Chemists. 18th ed. Gaithersburg: AOAC, 2005. Method 991.43.

LUSTOSA, B. H. B.; LEONEL, M.; MISCHAN, M. M. Efeito de parâmetros operacionais na produção de biscoitos extrusados de farinha de mandioca. Brazilian Journal of Food Technology, Campinas, v. 11, n. 1, p. 12-19, 2008.

JARDIM, D. C. P. Atividade de água e a estabilidade dos alimentos. In: MOURA, S. C. S. R.; GERMER, S. P. M. (Coord.). Reações de Transformação e Vida-de-prateleira de Alimentos Processados. 4. ed. Campinas: ITAL, 2010. p. 17-23. (Manual Técnico, n. 6).

MAIA, G. A.; CALVETE, Y. M. A.; TELLES, F. J. S.; MONTEIRO, J. C. S.; SALES, M. G. Eficiência da farinha desengordurada de gergelim como complemento protéico da farinha extrudada de caupi. Pesquisa Agropecuária Brasileira, Brasília, v. 34, 
Qualidade física, química e sensorial de biscoitos tipo cookies elaborados com a substituição parcial da farinha de trigo por farinha desengordurada de gergelim

CLERICI, M. T. P. S. et al.

n. 7, p. 1295-1303, 1999. http://dx.doi.org/10.1590/S0100204X1999000700023

MARANGONI, A. L. Potencialidade de Aplicação de Farinha de Yacon (Polymnia sonchifolia) em Produtos à Base de Cereais. 2007. 125 f. Dissertação (Mestrado em Tecnologia de Alimentos)-Faculdade de Engenharia de Alimentos, Universidade Estadual de Campinas, Campinas, 2007

MARETI, M. C.; GROSSMANN, M. V. E.; BENASSI, M. T. Características físicas e sensoriais de biscoitos com farinha de soja e farelo de aveia. Ciência e Tecnologia de Alimentos, Campinas, v. 30, n. 4, p. 878-883, 2010. http://dx.doi. org/10.1590/S0101-20612010000400007

MEILGAARD, M.; CARR, B. T.; CIVILLE, G. V. Sensory Evaluation Techniques. 4th ed. Florida: CRC Press, 2006. 387 p.

MELLO, V. D.; LAAKSONEN, D. E. Fibras na dieta: tendências atuais e benefícios à saúde na síndrome metabólica e no diabetes melito tipo 2. Arquivos Brasileiros de Endocrinologia e Metabolismo, São Paulo, v. 53, n. 5, p. 509-518, 2009. http:// dx.doi.org/10.1590/S0004-27302009000500004

MINOLTA. The Essentials of Imaging, Manual Guide. [s.I.]: Minolta Co. Ltd., 2006. p. 18-21.

MOHDALY, A. A. A.; SMETANSKA, I.; RAMADAN, M. F.; SARHAN, M. A.; MAHMOUD, A. Antioxidant potential of sesame (Sesamum indicum) cake extract in stabilization of sunflower and soybean oils. Industrial Crops and Products, Amsterdam, v. 34, p. 952-959, 2011. http://dx.doi.org/10.1016/j. indcrop.2011.02.018

MORAES, K. S.; ZAVAREZE, E. R.; MIRANDA, M. Z.; SALASMELLADO, M. M. Avaliação tecnológica de biscoitos tipo cookie com variações nos teores de lipídio e de açúcar. Ciência e Tecnologia de Alimentos, Campinas, v. 30, p. 233-242, 2010. Suplemento 1.

NASCIMENTO, E. M.G. C.; CARVALHO, C. W. P.; TAKEITI, C. Y.; FREITAS, D. G. C.; ASCHERI, J. L. R. Use of sesame oil cake (Sesamum indicum L.) on corn expanded extrudates. Food Research International, Amsterdam, v. 45, p. 434-443, 2012. http://dx.doi.org/10.1016/j.foodres.2011.11.009

PIZZINATTO, A.; MAGNO, C. P. R. S.; CAMPAGNOLLI, D. M. F. Avaliação e Controle de Qualidade da Farinha de Trigo. Campinas: ITAL, 1996. 67 p.
SARANTÓPOULOS, C. I. G. L.; OLIVEIRA, L. M.; CANAVESI, E. Requisitos de Conservação de Alimentos em Embalagens Flexíveis. Campinas: CETEA/ITAL, 2001. 215 p.

SCHOBER, T. J.; O'BRIEN, C. M.; McCARTHY, D.; DARNEDDE, A.; ARENDT, E. K. Influence of gluten-free flour mixes and fat powders on the quality of gluten-free biscuits. European Food Research and Technology, Berlim, v. 216, p. 216-376, 2003.

SILVA, M. R.; SILVA, M. A. A. P.; CHANG, Y. K. Use of jatobá (Hymenaea stigonocarpa Mart.) flour in the production of cookies and acceptance evaluation using univariate and multivariate sensory tests. Ciência e Tecnologia de Alimentos, Campinas, v. 18, n. 1, p-25-34, 1998.

SINDICATO DA INDÚSTRIA DE MASSAS ALIMENTÍCAS E BISCOITOS DO ESTADO DE SÃO PAULO - SIMABESP . Mercado Biscoitos. São Paulo: SIMABESP, 2009. Disponível em: <www. simabesp.org.br/site/mercado_biscoitos_simabesp.asp> Acesso em: 03 jun. 2012.

SOUZA, M. L.; RODRIGUES, R. S.; FURQUIM, M. F. G.; EL-DASH, A. A. Processamento de "cookies" de Castanha-do-Brasil. Boletim do CPPA, Curitiba, v. 19, n. 2, p. 381-390, 2001.

STATISTICAL ANALISYS SYSTEM INSTITUTE - SAS. The SAS for Windows: Release 9.1.3. Cary: SAS, 2003.

TIWARI, B. K.; MUTHUKUMARAPPAN, K.; O'DONNELL, C. P.; CHENCHAIAH, M.; CULLEN, P. J. Effect of ozonization on the rheological and colour characteristics of hydrocolloid dispersions. Food Research International, Amsterdam, v. 41 , n. 10, p. 1035-1043, 2008. http://dx.doi.org/10.1016/j. foodres.2008.07.011

UNIVERSIDADE ESTADUAL DE CAMPINAS - UNICAMP. Tabela Brasileira de Composição de Alimentos - TACO. 4. ed. rev. e ampl. Campinas: UNICAMP/NEPA, 2011. 161 p.

YOUNG, L.; CAUVAIN, S. P. Technology of Breadmaking. 2nd ed. [s.I.]: Springer, 2007. $464 \mathrm{p}$.

ZAMBRANO, F.; ORMENESE, R. C. S. C.; PIZZINATTO, A.; ANJOS, V. D. A.; BRAGAGNOLO, N. Cookies com Substituição Parcial de Gordura: Composição Centesimal, Valor Calórico, Características Físicas e Sensoriais. Brazilian Journal of Food Technology, Campinas, v. 5, p. 43-52, 2002

ZUCCO, F.; BORSUK, Y.; ARNTFIELD, S. D. Physical and nutritional evaluation of wheat cookies supplemented with pulse flours of different particle sizes. LWT - Food Science and Technology, Amsterdam, v. 44, p. 2070-2076, 2011. 